\title{
Subthalamic Nucleus and Sensorimotor Cortex Activity During Speech Production
}

\author{
๑DAnna Chrabaszcz, ${ }^{1}$ ○Wolf-Julian Neumann, ${ }^{2}$ Otilia Stretcu, ${ }^{3}$ Witold J. Lipski, ${ }^{4}$ @Alan Bush, ${ }^{4,5}$ \\ Christina A. Dastolfo-Hromack, ${ }^{4}$ Dengyu Wang, ${ }^{4,6}$ Donald J. Crammond, ${ }^{4}{ }^{\circledR}$ Susan Shaiman, ${ }^{7}$ Michael W. Dickey,

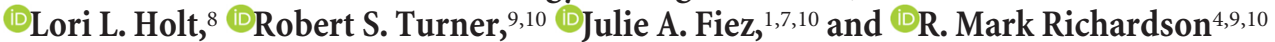 \\ ${ }^{1}$ Department of Psychology, University of Pittsburgh, Pittsburgh, Pennsylvania 15213, ${ }^{2}$ Movement Disorder and Neuromodulation Unit, Department of \\ Neurology, Campus Mitte, Charité, Universitätsmedizin Berlin, Berlin, Germany 10117, ${ }^{3}$ Machine Learning Department, School of Computer Science, \\ Carnegie Mellon University, Pittsburgh, Pennsylvania 15213, ${ }^{4}$ Brain Modulation Laboratory, Department of Neurological Surgery, University of Pittsburgh School of \\ Medicine, Pittsburgh, Pennsylvania 15213, ${ }^{5}$ Department of Physics, FCEN, University of Buenos Aires and IFIBA-CONICET, Buenos Aires, Argentina 1428, ${ }^{6}$ School \\ of Medicine, Tsinghua University, Beijing, China $100084,{ }^{7}$ Department of Communication Science and Disorders, University of Pittsburgh, Pittsburgh, Pennsylvania \\ 15213, ${ }^{8}$ Department of Psychology, Carnegie Mellon University, Pittsburgh, Pennsylvania 15213, ${ }^{9}$ Department of Neurobiology, University of Pittsburgh School of \\ Medicine, Pittsburgh, Pennsylvania 15213, and ${ }^{10}$ University of Pittsburgh Brain Institute, Pittsburgh, Pennsylvania 15213
}

The sensorimotor cortex is somatotopically organized to represent the vocal tract articulators such as lips, tongue, larynx, and jaw. How speech and articulatory features are encoded at the subcortical level, however, remains largely unknown. We analyzed LFP recordings from the subthalamic nucleus (STN) and simultaneous electrocorticography recordings from the sensorimotor cortex of 11 human subjects (1 female) with Parkinson's disease during implantation of deep-brain stimulation (DBS) electrodes while they read aloud three-phoneme words. The initial phonemes involved either articulation primarily with the tongue (coronal consonants) or the lips (labial consonants). We observed significant increases in high-gamma $(60-150 \mathrm{~Hz})$ power in both the STN and the sensorimotor cortex that began before speech onset and persisted for the duration of speech articulation. As expected from previous reports, in the sensorimotor cortex, the primary articulators involved in the production of the initial consonants were topographically represented by highgamma activity. We found that STN high-gamma activity also demonstrated specificity for the primary articulator, although no clear topography was observed. In general, subthalamic high-gamma activity varied along the ventral- dorsal trajectory of the electrodes, with greater high-gamma power recorded in the dorsal locations of the STN. Interestingly, the majority of significant articulatordiscriminative activity in the STN occurred before that in sensorimotor cortex. These results demonstrate that articulator-specific speech information is contained within high-gamma activity of the STN, but with different spatial and temporal organization compared with similar information encoded in the sensorimotor cortex.

Key words: deep brain stimulation; electrocorticography; Parkinson's disease; sensorimotor cortex; speech; subthalamic nucleus

Significance Statement

Clinical and electrophysiological evidence suggest that the subthalamic nucleus (STN) is involved in speech; however, this important basal ganglia node is ignored in current models of speech production. We previously showed that STN neurons differentially encode early and late aspects of speech production, but no previous studies have examined subthalamic functional organization for speech articulators. Using simultaneous LFP recordings from the sensorimotor cortex and the STN in patients with Parkinson's disease undergoing deep-brain stimulation surgery, we discovered that STN high-gamma activity tracks speech production at the level of vocal tract articulators before the onset of vocalization and often before related cortical encoding.

\section{Introduction}

Speech articulation constitutes a complex motor behavior involving a precise coordination of different parts of the vocal ap- paratus known as articulators (e.g., lips, tongue). Although recruitment of the cortical regions in the articulatory realization of speech is widely documented, the specific contributions of 
different subcortical structures remain largely unknown. Here, for the first time, we use LFP recordings from the subthalamic nucleus (STN) and simultaneous electrocorticography (ECoG) recordings from the sensorimotor cortex to investigate the role of the STN in speech articulation and to compare its spatial and temporal organization for encoding of speech articulators with that of the sensorimotor cortex.

Ample evidence has implicated the ventral-lateral orofacial area of the sensorimotor cortex as a principal cortical region for the neural representation of speech articulators. Electrical stimulation of this region produces somatotopically organized sensorimotor responses for the larynx, tongue, jaw, and lips along the ventral-dorsal orientation of the central sulcus, respectively (Penfield and Boldrey, 1937; Penfield, 1954; Woolsey et al., 1979; Breshears et al., 2015). fMRI studies generally provide corroborating evidence for the somatotopic cortical representation of the vocal tract effectors, among other body parts, albeit with a varying degree of overlap among individuals (Lotze et al., 2000; Hesselmann et al., 2004; Pulvermüller et al., 2006; Brown et al., 2008; Meier et al., 2008; Takai et al., 2010; Carey et al., 2017). Recently, ECoG studies have elaborated the notion of cortical articulatory somatotopy by revealing differentiated neural representations for fine-grained phonetic features and complex kinematics underlying speech articulation (Bouchard et al., 2013, 2016; Bouchard and Chang, 2014; Mugler et al., 2014; Lotte et al., 2015; Cheung et al., 2016; Ramsey et al., 2018; Chartier et al., 2018; Conant et al., 2018).

Anatomical connections between the sensorimotor cortex and the basal ganglia via a cortico-striatal-thalamic loop (Alexander et al., 1986) suggest that the basal ganglia, including the STN, may also participate in speech production. Indeed, indirect evidence from the lesion literature (Brunner et al., 1982; Damasio et al., 1982; Wallesch et al., 1983; Nadeau and Crosson, 1997), from clinical data on deep-brain stimulation (DBS) outcomes (Morrison et al., 2004; Witt et al., 2008; Aldridge et al., 2016; Knowles et al., 2018), and neurological disorders involving the basal ganglia (Logemann et al., 1978; Ho et al., 1998; Walsh and Smith, 2012) implicates the basal ganglia in many aspects of speech production. Direct evidence from electrophysiological recordings of STN activity during speech production shows a decrease in beta power during articulation of nonpropositional speech (Hebb et al., 2012) and speech-related changes in singleunit firing activity (Watson and Montgomery, 2006; Lipski et al., 2018). To our knowledge, however, no study has investigated the spatial and temporal distribution of speech-related neuronal activity for different articulators in the STN relative to the sensorimotor cortex. Given that the STN is anatomically subdivided into sensorimotor, limbic, and associative functional areas (Hamani et al., 2004; Temel et al., 2005; Haynes and Haber, 2013) and that a somatotopic organization for arms, legs, eyes, and face is observed within the motor territory of the STN in human and nonhuman primates (Monakow et al., 1978; DeLong et al., 1985; Wichmann et al., 1994; Rodriguez-Oroz et al., 2001; Starr et al., 2003; Theodosopoulos et al., 2003; Nambu, 2011), it is possible that a functional somatotopy for the vocal tract articulators is also maintained within the STN.

Institute NeuroDiscovery Pilot Research Award (R.M.R.). We thank the patients who participated in this study and the clinical staff who facilitated data collection.

The authors declare no competing financial interests.

Correspondence should be addressed to R. Mark Richardson at richardsonrm@upmc.edu.

https://doi.org/10.1523/JNEUROSCI.2842-18.2019

Copyright $\odot 2019$ the authors
Table 1. Subject demographic and clinical characteristics

\begin{tabular}{|c|c|c|c|c|c|c|c|}
\hline Subject & Gender & Age & Handedness & Education, y & $\begin{array}{l}\text { Duration } \\
\text { of } \\
\text { disease, y }\end{array}$ & $\begin{array}{l}\text { Hoehn } \\
\text { and Yahr } \\
\text { stage }\end{array}$ & $\begin{array}{l}\text { UPDRS } \\
\text { score } \\
\text { (off medication) }\end{array}$ \\
\hline 1 & Male & 71 & Not recorded & Not recorded & 6 & 2 & 35 \\
\hline 2 & Male & 60 & Right & 12 & 14 & 2 & 53 \\
\hline 3 & Male & 69 & Right & 14 & 9 & 2 & 46 \\
\hline 4 & Male & 61 & Right & 16 & 5 & 2 & 31 \\
\hline 5 & Male & 68 & Left & 16 & 8 & 2 & 50 \\
\hline 6 & Male & 57 & Not recorded & Not recorded & 7 & 2 & 44 \\
\hline 7 & Male & 82 & Right & 16 & 8 & 2 & 36 \\
\hline 8 & Male & 66 & Right & 19 & 7 & 2 & 45 \\
\hline 9 & Female & 71 & Right & 16 & 8 & 2 & 24 \\
\hline 10 & Male & 77 & Right & 18 & 10 & 2 & 27 \\
\hline 11 & Male & 60 & Right & 13 & 6 & 2 & 39 \\
\hline
\end{tabular}

We used a novel experimental paradigm in awake, speaking patients undergoing STN-DBS for Parkinson's disease, during which sensorimotor electrocorticography is recorded simultaneously with STN LFPs. We discovered that STN high-gamma (60$150 \mathrm{~Hz}$ ) activity is dynamic during the production of speech, exhibiting activity that tracks with specific articulatory motor features. Our data further suggest that spatial and temporal characteristics of the neural representations of speech articulators may differ between the cortex and STN.

\section{Materials and Methods}

Participants. Participants included 11 native English-speaking patients with Parkinson's disease (10 M/1 F, age: $67.5 \pm 7.7$ years, duration of disease: $8 \pm 2.4$ years) undergoing awake stereotactic neurosurgery for implantation of DBS electrodes in the STN. In addition to the clinical subcortical mapping and as part of an institutional review boardapproved research protocol, participants were temporarily implanted with subdural electrode arrays over the left ventral sensorimotor cortex. All patients completed Unified Parkinson's Disease Rating Scale (UPDRS) testing within 4 months before the surgery. Dopaminergic medication was withdrawn the night before surgery. Subjects' demographic and clinical characteristics are provided in Table 1. All procedures were approved by the University of Pittsburgh Institutional Review Board (Protocol \#PRO13110420) and all patients provided informed consent to participate in the study.

Stimuli and procedure. Participants performed a reading-aloud task during the subcortical mapping portion of the surgery in up to four recording sessions per patient, with 120 trials per session. The visual stimuli consisted of consonant-vowel-consonant (CVC) words and pseudowords presented on a computer screen. The stimuli were chosen from an existing stimulus set and were balanced along a number of psycholinguistic parameters such as phonological and orthographic neighborhood density, bigram frequency, phonotactic and biphone probability, etc. (for a detailed description of the stimuli, see Moore et al., 2017). For the purposes of the present study, the stimuli were grouped into two categories based on the primary articulator involved in the production of the initial consonants: words with word-initial labial consonants (i.e., those requiring closure or constriction of the air flow primarily using the lips) and words with word-initial coronal consonants (i.e., those requiring articulation primarily using the tongue). The labial consonants subsumed bilabial $(/ \mathrm{p} /, / \mathrm{m} /)$ and labiodental $(/ \mathrm{f} /, / \mathrm{v} /)$ phonemes; coronal consonants included alveolar $(/ \mathrm{s} /, / \mathrm{z} /, / \mathrm{t} /, / \mathrm{d} /, / \mathrm{l} /, / \mathrm{n} /)$, postalveolar $(/ \mathrm{S} /)$, and dental $(/ \theta /, / / /)$ phonemes.

The stimuli were created and presented by custom code running in the MATLAB environment (The MathWorks) using Psychophysics Toolbox extensions (Brainard, 1997). A schematic of the experimental procedure is shown in Figure 1. On each trial, participants were presented with a white cross against a black background during an intertrial interval, after which a green fixation cross appeared on the screen for $250 \mathrm{~ms}$ instructing the participants to get ready. It was followed by a variable interstimu- 
ITI

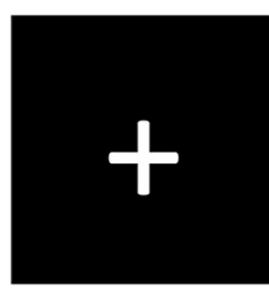

variable time preparatory cue

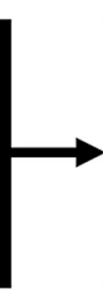

.

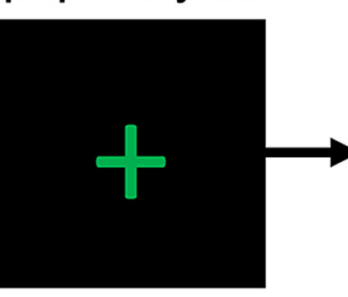

$250 \mathrm{~ms}$
ISI

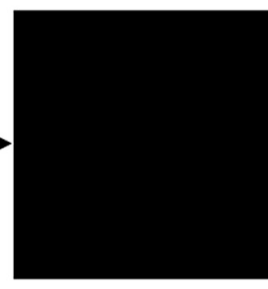

$500-1000 \mathrm{~ms}$ stimulus

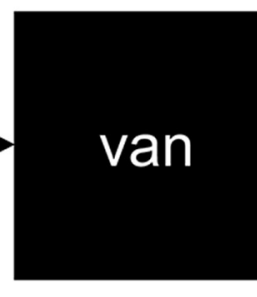

speech

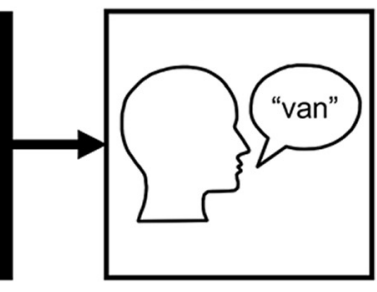

Figure 1. Experimental paradigm. ITI, Intertrial interval; ISI, interstimulus interval.

lus interval (500-1000 ms) during which the screen remained black. The stimulus word was then presented on the screen and participants were instructed to read it out loud. The stimulus word remained on the screen until participants made the response, after which the experimenter advanced the presentation to the next trial. All stimuli (120 trials per recording session) were pseudorandomized in order of presentation. Participants were familiarized with the task before surgery.

Audio recordings. Participants' reading aloud was recorded using an omnidirectional microphone (Audio-Technica ATR3350iS Mic, frequency response $50-18,000 \mathrm{~Hz}$, or PreSonus PRM1 Mic, frequency response $20-20,000 \mathrm{~Hz}$ ). The microphone was positioned at a distance of $\sim 8 \mathrm{~cm}$ from the subject's left oral angle of the mouth and oriented at an angle of $\sim 45$ degrees. A Zoom H6 digital recorder was used to record the audio signal at a sampling rate of $96 \mathrm{kHz}$. This signal was simultaneously recorded using a Grapevine Neural Interface Processor (Ripple) at a lower sampling rate of $30 \mathrm{kHz}$. The audio recordings were segmented and transcribed offline by phonetically trained communication science students using the International Phonetic Alphabet in a custom-designed graphical user interface implemented in MATLAB. The audio recordings were synchronized with the neural recordings using digital pulses delivered to the Neuro-Omega system (Alpha Omega) via a USB data acquisition unit (Measurement Computing, model USB-1208FS).

STN recordings. Subjects were implanted with DBS leads bilaterally, but LFPs were recorded during the administration of the reading-aloud task only for the left side surgery (see Fig. $2 A$ for an example of a lead trajectory). The LFP signal was acquired with the Neuro-Omega recording system using parylene insulated tungsten microelectrodes $(25 \mu \mathrm{m}$ in diameter, $100 \mu \mathrm{m}$ in length) with a stainless steel macroelectrode ring (0.55 $\mathrm{mm}$ in diameter, $1.4 \mathrm{~mm}$ in length) $3 \mathrm{~mm}$ above the tip of the microelectrode. The LFP signal was recorded at a sampling rate of $44 \mathrm{kHz}$ and was band-pass filtered at $0.075 \mathrm{~Hz}$ to $10 \mathrm{kHz}$. The microelectrodes targeted the dorsolateral area of the STN, as described previously (Lee et al., 2018). The microelectrodes were oriented on the microtargeting drive system using two or three trajectories of a standard cross-shaped BenGun array with a $2 \mathrm{~mm}$ center-to-center spacing: for mapping of the center, posterior, and medial tracts. The microelectrodes were advanced manually in $0.1 \mathrm{~mm}$ steps starting $10 \mathrm{~mm}$ above the defined target. The patients were subsequently implanted with DBS Medtronic 3389 leads with four platinum-iridium cylindrical macroelectrodes $1.27 \mathrm{~mm}$ in diameter, $1.5 \mathrm{~mm}$ in length, and $0.5 \mathrm{~mm}$ electrode spacing. The superior and inferior boundaries of the STN were determined by the neurophysiologist and neurosurgeon based on the characteristic STN single-unit neuronal activity obtained from the microelectrode recordings. The speech task was administered and LFP data acquired for up to four different depths within the STN per patient. As a result, LFP data from a total of 79 recording sites were obtained across all patients. For the most superficial recording sites within the STN, the macroelectrode ring may have been just superior to the dorsal border of STN. The locations of the macroelectrode contacts were determined using the semiautomatic approach implemented in the Lead-DBS toolbox (Horn and Kühn, 2015; Horn et al., 2019). In brief, postoperative CT scans were linearly coregistered with preoperative MRI scans and normalized to Montreal Neurological Institute (MNI) space. MNI-defined coordinates of macroelectrode contact locations were extracted for all subjects and are shown in Figure $2 B$.
Cortical recordings. In addition to the clinical subcortical mapping procedure, all patients were also temporarily implanted with subdural electrode arrays over the cortical surface of the left hemisphere, which were inserted through the burr hole after opening the dura but before the insertion of subcortical guide tubes. The ECoG signal was acquired at 30 $\mathrm{kHz}$ using the Grapevine Neural Interface Processor. Most subjects were implanted with 6- or 28-channel electrode strips (Ad-Tech Medical) except for two subjects who were implanted with either a 36- or 54channel PMT electrode strips each (PMT). Depending on the type of the electrodes, the electrodes varied 1,2, or $4 \mathrm{~mm}$ in diameter and 3, 4, or 10 $\mathrm{mm}$ in center-to-center spacing. The placement of the electrode strips was targeted at the ventral sensorimotor cortex by using stereotactic coordinates to mark the scalp over this region and advancing the subdural strips in the direction of this overlying visual marker. A total of 198 electrodes were placed on the cortex, but only 125 were included in the analyses: those that were confined to the sensorimotor cortex as determined in the patients' native brain space (Fig. $2 C$ shows these locations in MNI space). Localization of the electrodes on the cortical surface was reconstructed from the following: (1) the intraoperative fluoroscopic images $(512 \times 512$ pixels; General Electric OEC 9900), (2) the coregistered preoperative and postoperative CT images obtained after placement of the Leksell frame, and (3) preoperative MRI scans according to the semiautomated method described in Randazzo et al. (2016). Electrode locations were then registered to the common brain space using the MNI template (ICBM152) with Brainstorm (Tadel et al., 2011) (https:// neuroimage.usc.edu/brainstorm/). Subjects' MNI-defined ECoG electrodes that were constrained to the sensorimotor cortex in native space are presented in 3D MNI space in Figure 2D.

Data selection. Of the 11 subjects who participated in the study, STN data for one subject (Subject 2) was not recorded due to a technical error. ECoG data from two subjects contained excessive artifacts in the signal (Subjects 7 and 10) and were excluded from the analysis. Trials were included in the analysis if a student coding the data was able to unambiguously identify a subject's spoken response, a subject's spoken response constituted the stimuli's targeted CVC structure, and a subject's response included the stimuli's targeted phonemes. On the basis of these criteria, 359 (9.8\%) of a total of 3669 recorded trials were rejected.

Electrophysiological data processing. Data processing was performed using custom code based on the Statistical Parametric Mapping (SPM12) (Wellcome Department of Cognitive Neurology, London) (http://www. fil.ion.ucl.ac.uk/spm/software/spm12/) and Fieldtrip (Oostenveld et al., 2011) toolboxes implemented in MATLAB. The data were resampled to a sampling frequency of $1 \mathrm{kHz}$. To minimize noise and artifactual electrode cross talk in the signal, the data were re-referenced offline using a common average referencing procedure applied over blocks of electrodes connected by the same head stage connector for the ECoG recordings and using a common average referencing procedure for the STN recordings. A $1 \mathrm{~Hz}$ high-pass filter and a $58-62 \mathrm{~Hz}$ notch filter were applied to remove cardioballistic artifacts and line noise, respectively. The signal was then aligned with the presentation of the green cross cue for subsequent baseline epoching and with the vowel onset (the transition between the initial consonant and the subsequent vowel, CV) for speech response epoching. The CV transition was used to separate the consonantal component from the subsequent vocalic component in subjects' spoken responses as described previously (Bouchard et al., 2013). For 


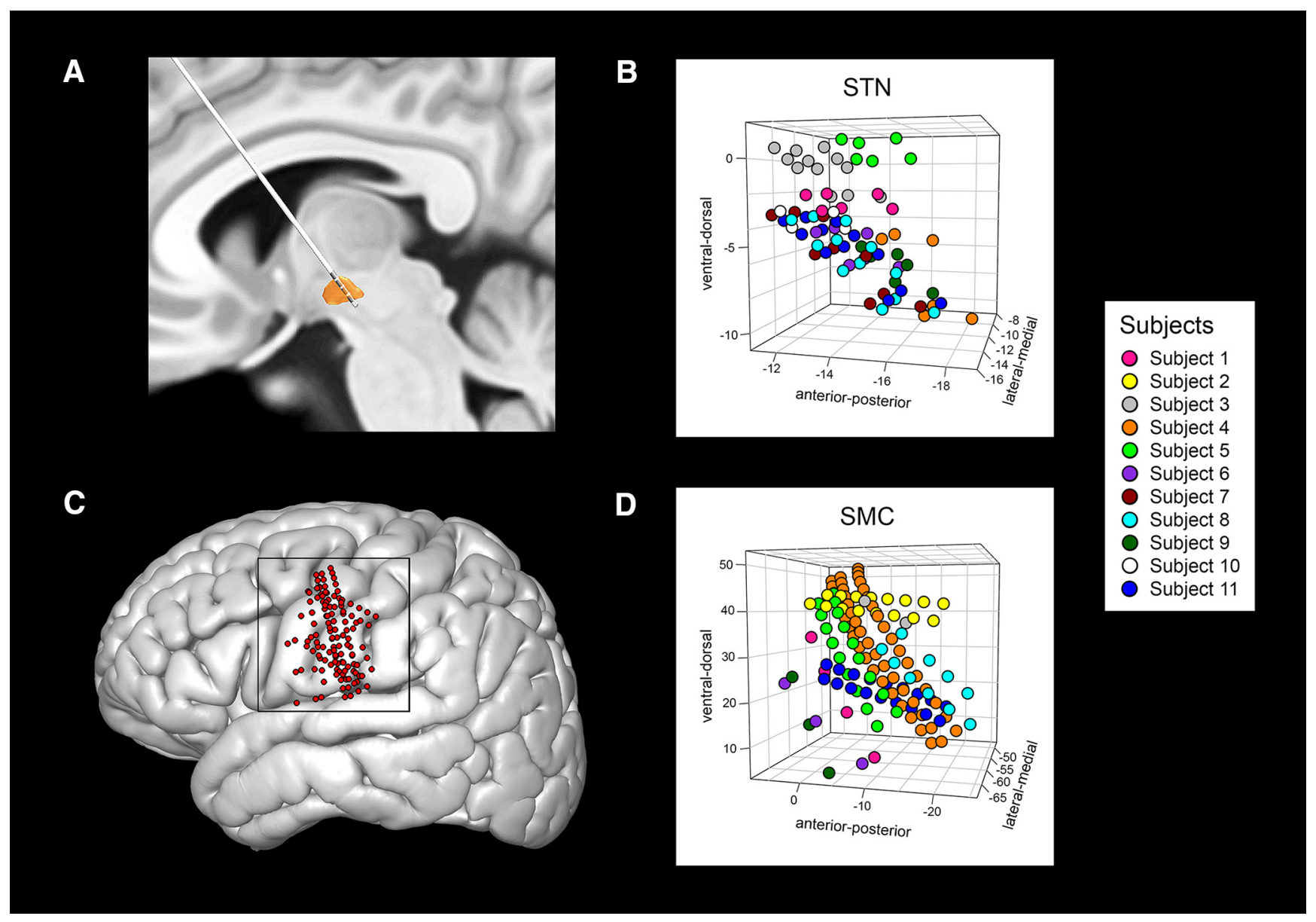

Figure 2. Location of recording sites in the MNI-defined space. A, Example trajectory of the DBS lead through the left STN shown on the DISTAL atlas by Ewert et al. (2018). B, MNI-defined coordinates (in millimeters) of recording sites in the STN plotted for all subjects in 3D space. C, Reconstructed locations of all ECoG electrodes in the sensorimotor cortex that were included in the study $(n=125)$, coregistered, and plotted on the cortical surface of the MNI brain space. $\boldsymbol{D}$, MNI-defined coordinates (in millimeters) of the EC $0 \mathrm{G}$ contacts on the sensorimotor cortex plotted for all subjects in 3D space. In $\boldsymbol{B}$ and $\boldsymbol{D}$, each subject's electrodes are mapped with a different color.

artifact rejection, data were visually inspected over 6000-ms-long time windows surrounding baseline and vowel onset; time widows with residual artifacts and excessive noise were excluded from analysis, resulting in an additional $4.8 \%$ data rejection. The remaining data underwent a time-frequency transformation using Morlet wavelets with 7 cycles over frequencies between 1 and $200 \mathrm{~Hz}$ in incrementing steps of $2 \mathrm{~Hz}$. The resulting signal was normalized using $z$-scores calculated relative to a 1000-ms-long baseline period ( $250 \mathrm{~ms}$ before and $750 \mathrm{~ms}$ after green cross presentation). A time-varying analytic amplitude in the highgamma-frequency range $(60-150 \mathrm{~Hz})$ was extracted for further analyses because it has been consistently reported to reflect changes in sensory, motor, and cognitive functions, including speech (Crone et al., 1998; Edwards et al., 2005; Bouchard et al., 2013).

Experimental design and statistical analysis. All statistical analyses were performed in MATLAB 2017a and R version 3.4.4 (R Core Team, 2018). A within-subjects experimental design was used, in which all subjects $(n=11)$ received trials with both lip and tongue articulations (120 trials per recording session). Recorded LFPs from the sensorimotor cortex and the STN were analyzed separately using the same statistical procedures. For the analysis of the LFPs throughout speech production, a time window of $1000 \mathrm{~ms}$ ( $500 \mathrm{~ms}$ before and $500 \mathrm{~ms}$ after the vowel onset) encompassing subjects' whole spoken response was used. For the analysis of the articulatory specificity of the initial consonant, a $500 \mathrm{~ms}$ time window preceding the vowel onset was used. Although durations of the wordinitial consonants (as measured from the acoustic output) were on average $130 \mathrm{~ms}$ (coronal consonants: $139 \mathrm{~ms}$, labial consonants: $106 \mathrm{~ms}$, $\left.t_{(46799)}=-42.29, p<0.001\right)$, a broader time window of $500 \mathrm{~ms}$ allowed examination of potential pre-articulatory neuronal activity. To analyze high-gamma activity elicited during the speech task, a series of fitted linear mixed-effects models (LMEMs) with restricted maximum likelihood estimation were performed using lme4 (Bates et al., 2015) and lmerTest (Kuznetsova et al., 2017) packages. Subjects were entered as random effects to account for subject-specific idiosyncrasies. Model comparisons were performed via backward elimination of fixed effects and their interactions to measure the goodness of model fit without unnecessary parameter overfitting using the Akaike information criterion (Akaike, 1974). To perform correlation analyses between the observed speech and articulatory response and electrode location coordinates in the MNI space, we applied a Spearman's rank correlation test. Generally, to assess statistical differences of speechrelated changes in the brain response, we used Welch two-sample $t$ tests when the data were found not to deviate significantly from normality; when the data were not normally distributed, nonparametric Wilcoxon's ranksum or signed-rank tests (to determine the significance of response compared with baseline) were used. To assess normality of the data distribution, a one-sample Kolmogorov-Smirnov test was used; a two-sample Kolmogorov-Smirnov test was used to compare STN and cortical datasets. The false discovery rate (FDR) method (as described in Benjamini and Hochberg, 1995 ) was used at $\alpha=0.05$ to control for multiple comparisons. Effect sizes were estimated with Hedges' $g$ (Hedges, 1981); effects larger than 0.5 were considered large according to Sawilowsky (2009).

\section{Results}

Behavioral response

Subjects' behavioral performances are summarized in Table 2. Across subjects, the mean latency from seeing the stimulus word 
Table 2. Subject recording and behavioral performance characteristics

\begin{tabular}{|c|c|c|c|c|c|c|c|c|}
\hline Subject & $\begin{array}{l}\text { Cortical } \\
\text { recording }\end{array}$ & $\begin{array}{l}\text { No. of cortical } \\
\text { electrode } \\
\text { contacts }\end{array}$ & $\begin{array}{l}\text { STN } \\
\text { recording }\end{array}$ & $\begin{array}{l}\text { No. of STN } \\
\text { electrode } \\
\text { contacts }\end{array}$ & $\begin{array}{l}\text { Rejected } \\
\text { trials, \% }\end{array}$ & $\begin{array}{l}\text { Mean no. of } \\
\text { included trials } \\
\text { per session }\end{array}$ & $\begin{array}{l}\text { Spoken } \\
\text { response } \\
\text { latency (SD), s }\end{array}$ & $\begin{array}{l}\text { Spoken } \\
\text { response } \\
\text { duration (SD), s }\end{array}$ \\
\hline 1 & Yes & 6 & Yes & 6 & 34.2 & 66 & $1.60(0.40)$ & $0.59(0.13)$ \\
\hline 2 & Yes & 28 & Not used & Not used & 20.8 & 92.5 & $1.70(0.60)$ & $0.77(0.20)$ \\
\hline 3 & Yes & 6 & Yes & 12 & 4.5 & 110 & $1.18(0.50)$ & $0.52(0.09)$ \\
\hline 4 & Yes & 54 & Yes & 6 & 4.2 & 110.5 & $1.12(0.38)$ & $0.65(0.14)$ \\
\hline 5 & Yes & 28 & Yes & 6 & 4.6 & 103.5 & $0.70(0.12)$ & $0.62(0.17)$ \\
\hline 6 & Yes & 6 & Yes & 6 & 5 & 110.5 & $1.27(0.43)$ & $0.46(0.11)$ \\
\hline 7 & Not used & Not used & Yes & 9 & 22.3 & 59.3 & $2.62(1.83)$ & $0.43(0.08)$ \\
\hline 8 & Yes & 28 & Yes & 12 & 2.1 & 114 & $0.85(0.33)$ & $0.63(0.13)$ \\
\hline 9 & Yes & 6 & Yes & 6 & 8.6 & 91.67 & $1.12(0.49)$ & $0.97(0.36)$ \\
\hline 10 & Not used & Not used & Yes & 4 & 12.7 & 75.5 & $1.21(0.43)$ & $0.54(0.10)$ \\
\hline 11 & Yes & 36 & Yes & 12 & 7.1 & 105.3 & $0.99(0.65)$ & $0.43(0.11)$ \\
\hline
\end{tabular}

on the screen to producing the word was $1.34 \pm 0.51 \mathrm{~s}$; the mean duration of the spoken response was $0.59 \pm 0.16 \mathrm{~s}$. The severity of the disease symptoms as measured by the UPDRS off medication did not account for variation in response latency (estimated coefficient $=-0.006, \mathrm{SE}=0.018, t=-0.23, p=0.77$ ) or response duration (estimated coefficient $=-0.003, \mathrm{SE}=0.005, t=$ $-0.63, p=0.54$ ). Average response accuracy was $88.5 \%$, although subjects 1,2 , and 7 produced many nontarget responses (incomplete words and/or nontarget phonemes), resulting in a high percentage of rejected trials $(>20 \%)$.

\section{Speech-related activity}

STN LFP activity showed significant time-frequency modulations relative to baseline (Fig. $3 A$ ) that were comparable to those obtained from the sensorimotor cortex (Fig. $3 B$ ). There were significant decreases in $z$-scored spectral power in the alpha $(8-12 \mathrm{~Hz})$ and beta $(12-30 \mathrm{~Hz})$ frequency bands and significant increases in $z$-scored power at high-frequency ranges relative to baseline, as determined by the Wilcoxon's signed-rank test ( $\alpha=$ 0.05, FDR corrected). Increases in the spectral power occurred from 60 to $180 \mathrm{~Hz}$ for STN sites and from $50 \mathrm{~Hz}$ and onward for the cortical sites. In both cases, significant high-frequency modulations occurred $\sim 400 \mathrm{~ms}$ before speech onset and persisted until $\sim 100 \mathrm{~ms}$ before speech offset for STN activity and until $\sim 100$ ms after speech offset for sensorimotor cortex activity. A more detailed examination of the $z$-scored spectral power in the high-gamma frequency range over the spoken response window ( $500 \mathrm{~ms}$ before vowel onset and $500 \mathrm{~ms}$ after vowel onset) showed that, in $86 \%(68 / 79)$ of STN sites and 95\% (119/125) of sensorimotor cortex ECoG sites, high-gamma power was significantly greater than baseline (Wilcoxon's signed-rank test at $\alpha=0.05$, FDR corrected). Significant increases in average high-gamma power during speech production were observed in all patients in both structures. The subjects' symptom severity (as measured by a total UPDRS score) was not correlated (Spearman's rank-order correlation test) with the average high-gamma activity for the speech response window either in the STN $\left(r_{\mathrm{s}(10)}=0.37, p=\right.$ $0.29)$ or the sensorimotor cortex $\left(r_{\mathrm{s}(9)}=0.43, p=0.24\right)$. In the STN, averaged high-gamma power significantly correlated with the location of recording sites along the ventral-dorsal axis in the MNI space $\left(r_{\mathrm{s}(79)}=0.53, p<0.001\right)$ and anterior-posterior axis $\left(r_{\mathrm{s}(79)}=0.36, p=0.0012\right)$, but not the lateral-medial axis $\left(r_{\mathrm{s}(79)}\right.$ $=0.03, p=0.78)$. In contrast, we found no significant correlation between high-gamma power and the location of the recording sites on the sensorimotor cortex. To explain the observed variation in the high-gamma power across STN recording sites and to control for subject variability, we fitted LMEMs. The most parsi- monious model included average high-gamma power as a dependent variable, subjects as a random effect, and the location of recording sites along the ventral-dorsal axis (the MNI-defined $z$-coordinate) as a fixed effect. The outcome of the LMEM suggests that, even after taking subject-to-subject variability into account, high-gamma power changed significantly from dorsal to ventral parts of the STN, with greater high-gamma power observed dorsally (estimated coefficient $=0.017, \mathrm{SE}=0.005, t=$ 3.19, $p=0.004)$. Mixed-effects modeling of the high-gamma response in the sensorimotor cortex did not yield significant effects.

\section{Representation of articulators}

To determine the spatial distribution of speech articulator representations within the STN and sensorimotor cortex, we compared (Welch's two-sample $t$ test) high-gamma power averaged over the prevocalic time window of $500 \mathrm{~ms}$ for trials with wordinitial coronal (tongue) consonants versus trials with wordinitial labial (lips) consonants at each recording site. We used the outcome of the $t$ test and the sign of the $t$-value to detect discriminative articulatory activity. For example, a significant $(\alpha=0.05)$ and positive $t$-value indicated that a given site's average highgamma power was greater for consonants articulated with the lips than those articulated with the tongue; conversely, negative $t$-values indicated tongue-related activity. MNI-defined locations of cortical and STN articulator-responsive sites are plotted in Figure 4, $A$ and $C$, respectively. An example of what constituted articulator-discriminative activity is shown for representative recording sites in Figure 4, $B$ and $D$. The remaining sites at which a significant increase in high-gamma power was observed produced an undifferentiated activity; that is, they were equally active during articulation of both coronal and labial consonants. The discriminative sites within the STN included 18 (23\%) of a total of 79 electrodes: five sites exhibited greater high-gamma activity during articulation with the lips; 13 sites were most active during articulation with the tongue; the discriminative cortical sites included 37 (30\%) of a total of 125 electrodes: 19 sites showed lips-preferred activity and 18 sites showed tonguepreferred activity (Fig. 5C). Of the eight subjects with both STN and cortical data, three were found to have articulatordiscriminative sites in both STN and sensorimotor cortex, two subjects showed articulator-discriminative activity only in the STN, two subjects had discriminative sites only in the sensorimotor cortex, and one subject did not show discriminative sites in either of the structures. One subject who only had ECoG data showed articulator-discriminative sites. Of the two remaining subjects who only had STN data, articulator-discriminative sites 


\section{STN}
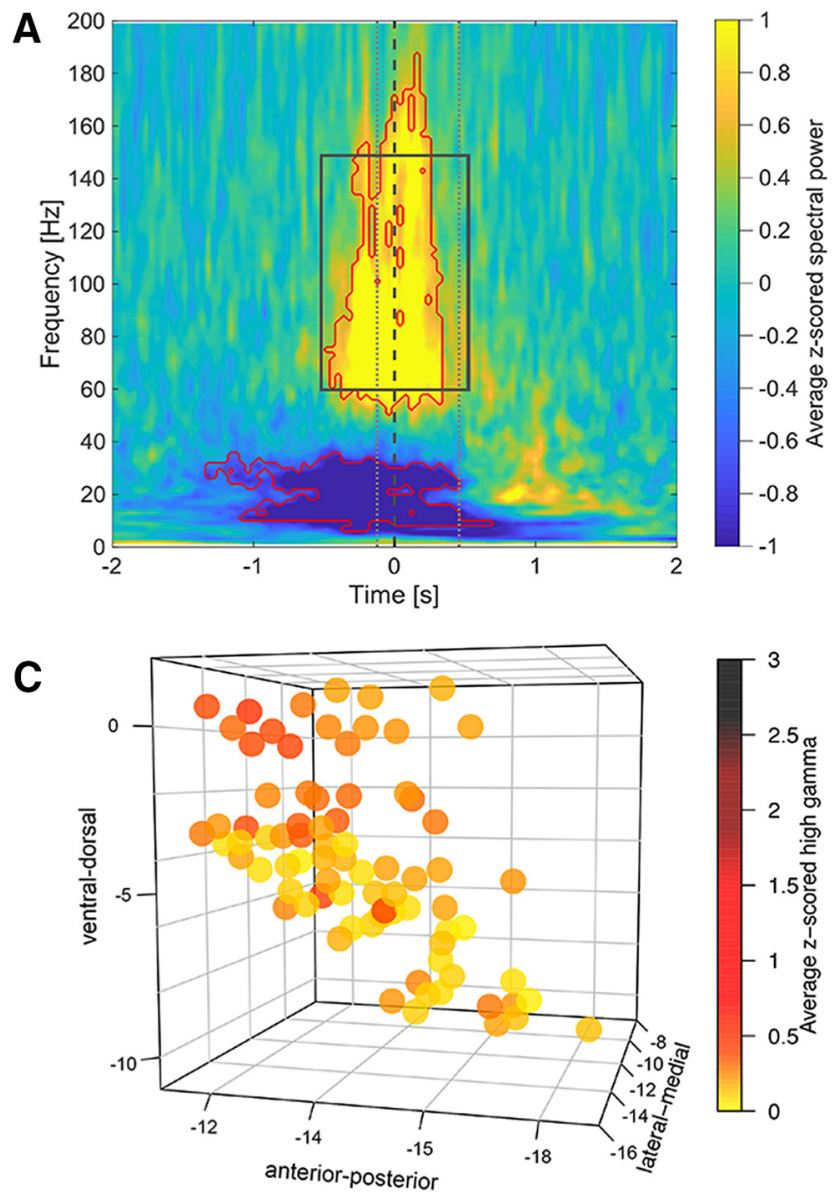

SMC
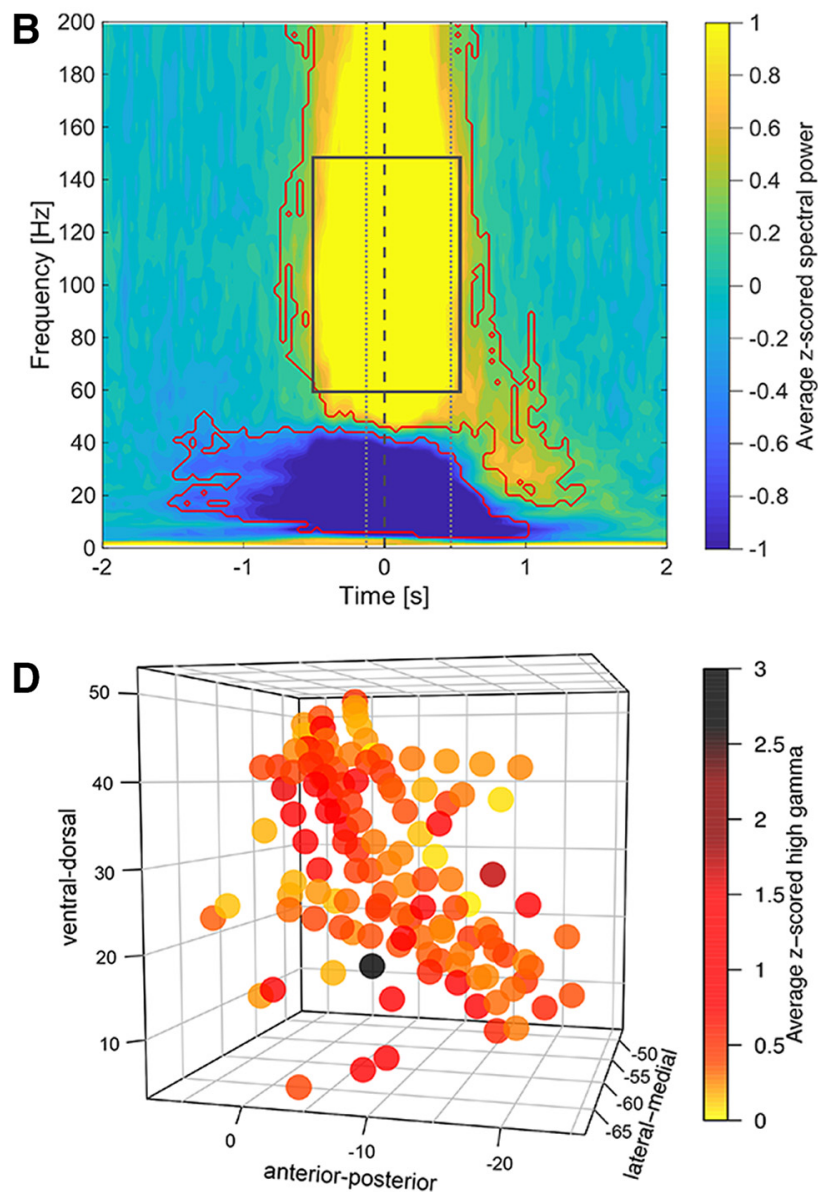

Figure 3. STN and sensorimotor cortex (SMC) show speech-production-related time-frequency modulations. $\boldsymbol{A}, \boldsymbol{B}$, Grand average of STN $(\boldsymbol{A})$ and SMC (B) oscillatory activity (average z-scored spectral power) across all recording sites and all trials aligned to vowel onset (time $=0 \mathrm{~s}$, gray dashed vertical line). Significant modulations compared with baseline are marked in red contour (Wilcoxon's signed-rank test, $p<0.05$, FDR corrected). Average speech production onsets and offsets are marked with gray dotted vertical lines. Rectangles with gray solid lines mark the time window ( $\pm 500 \mathrm{~ms}$ from vowel onset) for the analysis of speech production-related high-gamma (60-150 Hz) activity. C, D, z-scored high-gamma (60-150 Hz) power averaged for the $1 \mathrm{~s} \mathrm{time}$ window ( $\pm 500 \mathrm{~ms}$ from vowel onset) plotted in 3D space for each subject's STN $(\boldsymbol{C})$ and SMC $(\boldsymbol{D})$ recording site. The location of recoding sites is provided in MNI coordinates.

were observed only for one patient. In the STN, recording sites with tongue-preferred activity appeared to be located more dorsally compared with those selective for lips; however, the obtained $t$-values did not correlate significantly with any of the three spatial orientation planes through the recording locations (ventral-dorsal, anterior-posterior, or lateral-medial) according to a Spearman's rank-order correlation test. Modeling of the articulatory activity in the STN with a mixed-effects regression approach did not yield significant effects (the most parsimonious model included subjects as a random effect and recording locations along the lateral-medial axis, the MNI-defined $x$-coordinate, as a fixed effect). In the sensorimotor cortex, $t$-values correlated significantly with the location of recording sites along the ventral-dorsal $\left(r_{\mathrm{s}(125)}=-0.39, p<-0.001\right)$ and lateral-medial $\left(r_{\mathrm{s}(125)}=-0.35, p=<0.001\right)$ axes. Modeling the articulatory effect with LMEMs produced similar results. Keeping subjects as a random effect, the most parsimonious models yielded a significant effect of the recording location along the ventral-dorsal (estimated coefficient $=0.064, \mathrm{SE}=0.022, t=$ 2.98, $p=0.004$ ) and the lateral-medial (estimated coefficient $=$ $0.148, \mathrm{SE}=0.053, t=2.6, p=0.011$ ) axes. Therefore, taking subject-to-subject differences into account, the articulatorrelated activity in the sensorimotor cortex appeared to be somatotopically organized, with the recording sites exhibiting encoding of lip articulations located more dorsally (and medially due to the cortex curvature) and sites exhibiting encoding of tongue articulations distributed more broadly over the ventrallateral part of the sensorimotor cortex.

To quantify the time course of the articulatory neural encoding, we examined the distribution of average high-gamma activity for all tongue versus lips trials at the identified articulator-discriminative sites in the STN $(n=18)$ and the sensorimotor cortex $(n=37)$ (Fig. $5 A, B)$. A two-sample Kolmogorov-Smirnov test showed that the STN and cortical data had significantly different distributions $\left(D_{(55)}=0.22, p<0.001\right)$. In the sensorimotor cortex, high-gamma activity for both tongue and lips trials was more tightly distributed and peaked around the time of vowel onset, whereas activity in the STN had two peaks, one $\sim 80 \mathrm{~ms}$ before consonant onset and one $120 \mathrm{~ms}$ after vowel onset. The second, post-vocalic peak in high-gamma activity in the STN may reflect activity related to the articulation of the word-final consonant. However, because our stimulus set was not designed to counterbalance lip and tongue features across all the phonemes in each syllable, we cannot rule out other possibilities such as activity related to vowel articulation or mid-word co-articulatory processes. In the pre-vocalic $500 \mathrm{~ms}$ window cor- 
A

STN

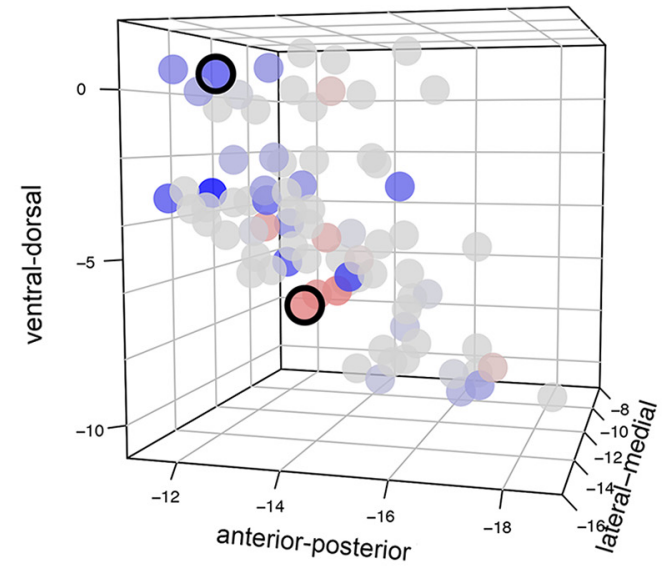

Tongue

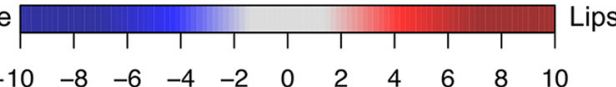

t-value

C

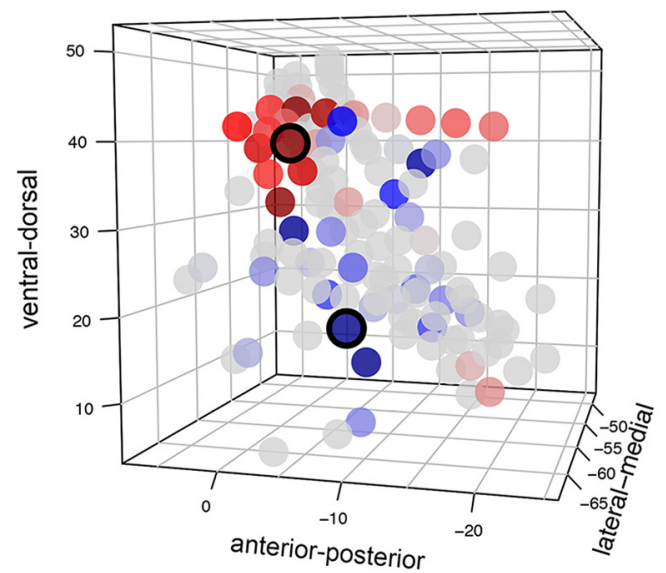

Tongue

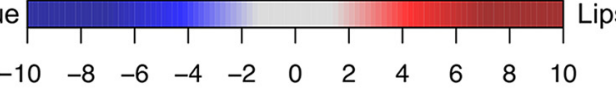

t-value
B

i)

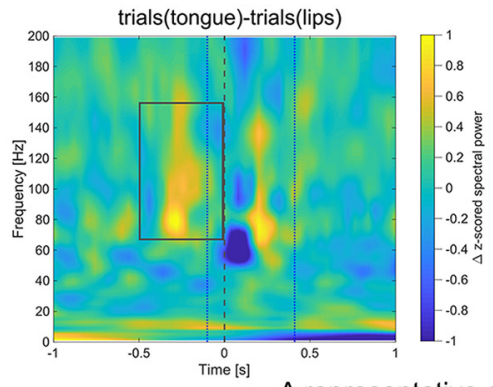

A representative electrode for tongue

iii)
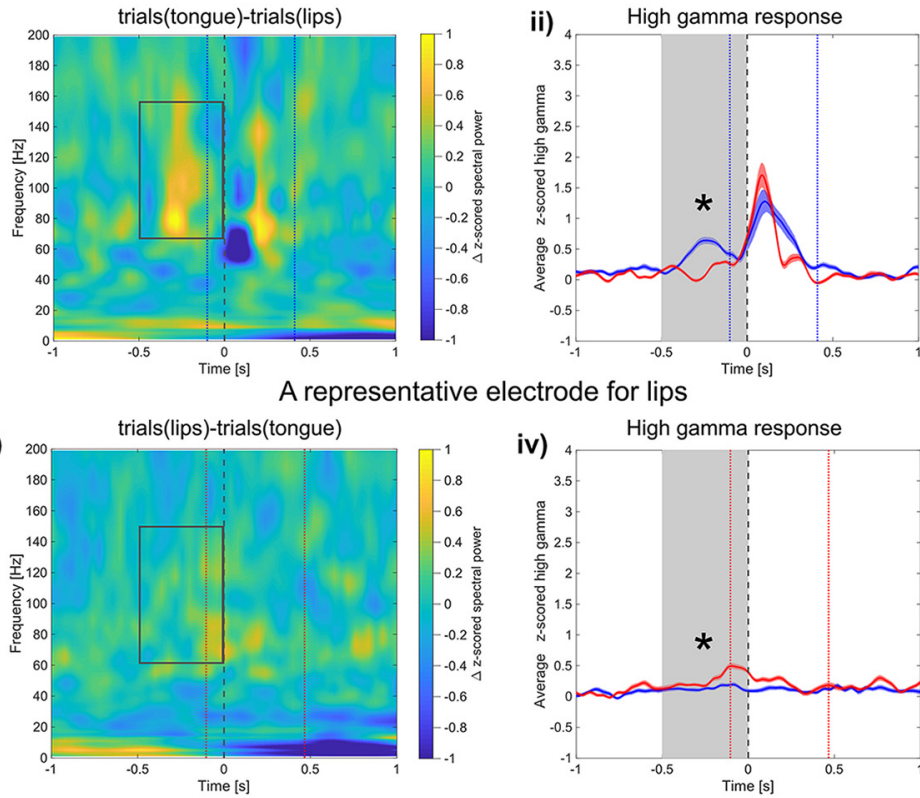

iv) $4 \quad$ High gamma response

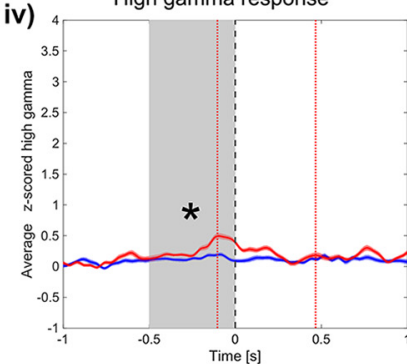

Articulator $\square$ Tongue $\square$ Lips

D

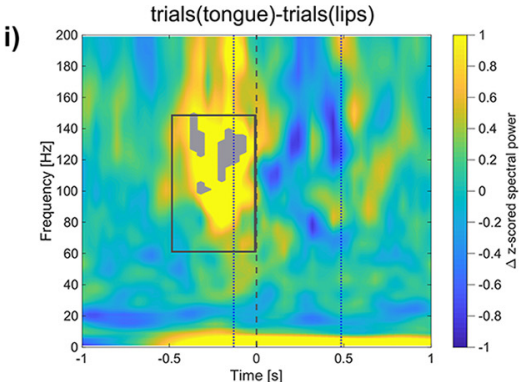

A representative electrode for tongue

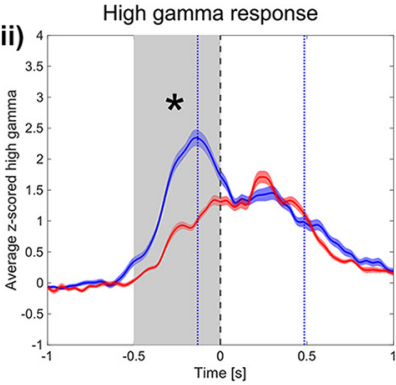

A representative electrode for lips

iii)

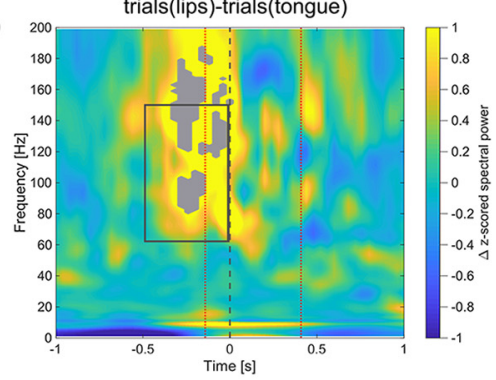

iv)

High gamma response

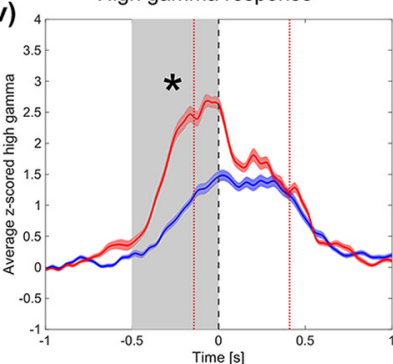

Figure 4. Spatial distribution of tongue-and lip-preferred articulatory activity in the MNI-defined STN space and sensorimotor cortex (SMC). A, C, Outcome of a series of t tests comparing z-scored high-gamma power (averaged for a 500-ms-long time window before vowel onset) during articulation of tongue consonants versus lip consonants for each STN (A) and SMC (C) recording site. Opacity of the circles varies with the magnitude of the $t$-value: negative $t$-values (in blue shades) suggest a greater response to tongue; positive $t$-values (in red shades) suggest a greater response to lips (Welch's two-sample $t$ test, $p<0.05$ ). Note that the obtained $t$-values for the SMC sites differed significantly along the ventral-dorsal and lateral-medial axes (Spearman's rank-order correlation test, $p<0.01$ ), suggesting articulator-discriminative somatotopy. Circles with black outline mark representative sites for tongue and lips, the articulatory activity of which is plotted on the right. $\boldsymbol{B}, \boldsymbol{D}$, Examples of representative tongue-preferred and lips-preferred sites for STN $(\boldsymbol{B})$ and SMC (D). A subtraction time-frequency representation is shown for the tongue-preferred site after time-frequency representation for all trials with lip consonants is subtracted from time-frequency representation for all trials with tongue consonants (i) and for the lip-preferred site after time-frequency representation for all trials with tongue consonants is subtracted from time-frequency representation for all trials with lip consonants (iii). Gray-filled contours mark significant time-frequency differences between the two conditions (Wilcoxon's rank-sum test, $p<0.05$, FDR corrected). Rectangles with gray solid lines mark the time window (from $500 \mathrm{~ms}$ before vowel onset until vowel onset) for the analysis of articulator-specific high-gamma $(60-150 \mathrm{~Hz})$ activity. Differences in averaged $z$-scored high-gamma power elicited by trials with the tongue articulation versus the lip articulation are shown for tongue-specific (ii) and lip-specific (iv) sites (significant differences are marked with asterisks, Welch's two-sample $t$ test, $p<0.05$ ). Gray bands mark the time window (from $500 \mathrm{~ms}$ before vowel onset until vowel onset) across which high-gamma power was averaged for the analysis of articulator-specific activity. Throughout $i$-iv, gray dashed vertical line represents vowel onset (time $=0$ s). Dotted vertical lines represent spoken response onsets and offsets for trials with tongue consonants (blue) and trials with lip consonants (red). 
A

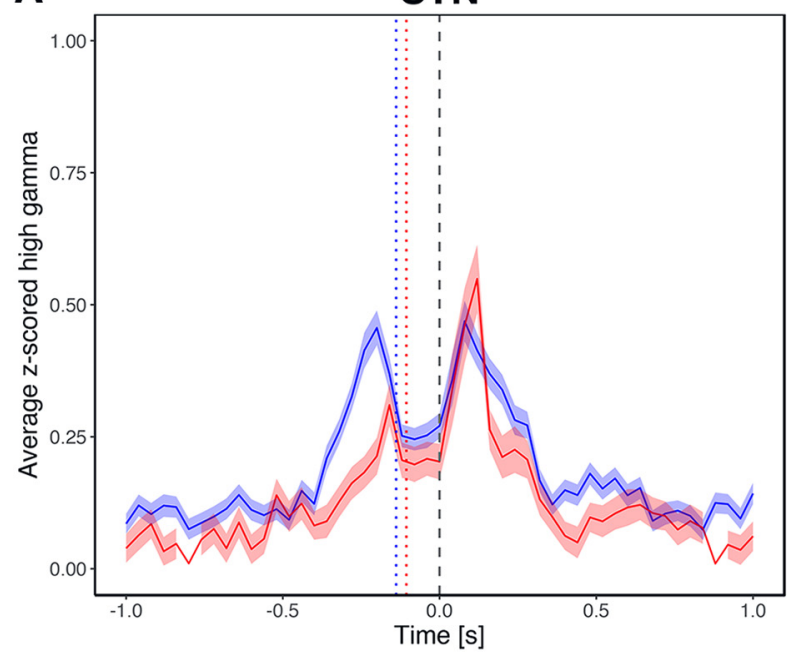

C

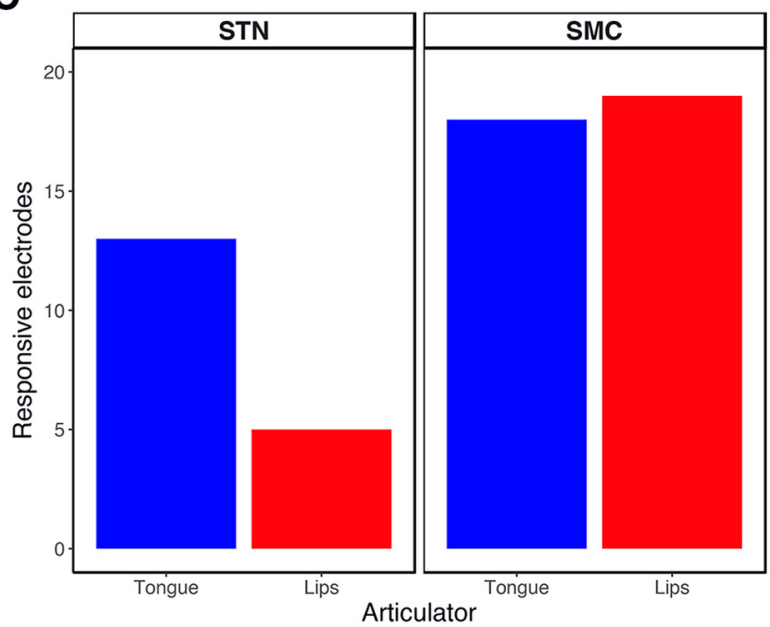

B

SMC
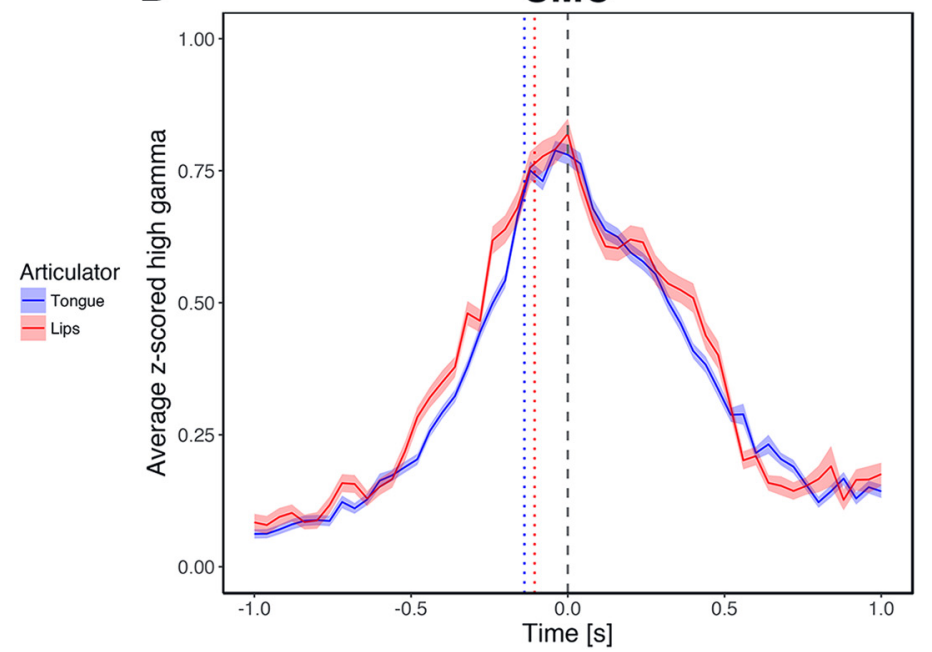

D

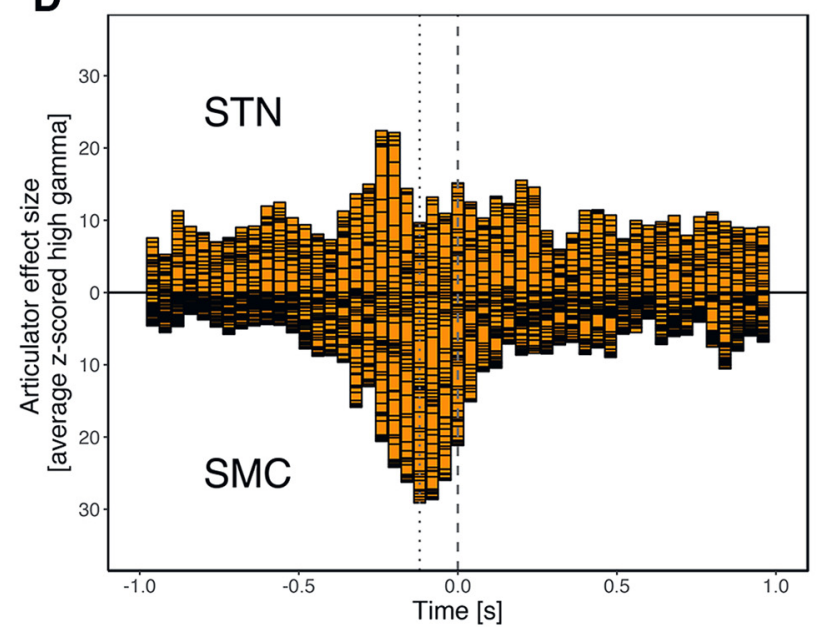

Figure 5. Time course of the articulatory encoding at articulator-discriminative recording sites in the STN and sensorimotor cortex (SMC). $\boldsymbol{A}, \boldsymbol{B}$, Average high-gamma activity at the STN ( $\boldsymbol{A}$ ) and SMC ( $\boldsymbol{B})$ articulator-responsive recording sites for trials with word-initial tongue (coronal) and word-initial lip (labial) consonants. $\boldsymbol{C}$, Number of articulator-responsive electrodes in the STN (a total of $23 \%$ ) and SMC (a total of $30 \%$ ) broken down by articulator type. D, Distribution of the effect sizes (Hedges' $g$ ) quantifying the difference in average $z$-scored high-gamma power between trials with word-initial coronal and word-initial labial consonants at each time point of the STN and SMC recordings. Throughout $\boldsymbol{A}, \boldsymbol{B}$, and $\boldsymbol{D}$, gray dashed vertical lines represent vowel onset (time $=0$ s) and dotted vertical lines represent consonant onset.

responding to the consonants of interest, the time of peak highgamma activity in the STN preceded that in the sensorimotor cortex (sensorimotor cortex: mean peak time $=-0.07 \mathrm{~s}, \mathrm{SD}=$ $0.08 \mathrm{~s}$; STN: mean peak time $=-0.16 \mathrm{~s}, \mathrm{SD}=0.1 \mathrm{~s}), t_{(27.64)}=$ $3.36, p=0.002)$. The mean change in amplitude of high-gamma activity in the $500 \mathrm{~ms}$ time window was significantly greater at cortical sites $($ mean $=0.98, \mathrm{SD}=0.79)$ compared with STN sites $($ mean $\left.=0.58, \mathrm{SD}=0.41): t_{(52.65)}=2.51, p=0.02\right)$. Within the STN, mean high-gamma amplitude was greater during the tongue trials (mean $=0.3, \mathrm{SD}=0.19)$ compared with the lips trials $($ mean $=0.17, \mathrm{SD}=0.06):\left(t_{(20.83)}=2.74, p=0.012\right)$, whereas no difference in high-gamma amplitude between the two articulators was observed at cortical sites.

Additionally, to identify the times at which the difference in high-gamma activity for tongue versus lip articulations was the largest, regardless of the underlying magnitude of high-gamma activity, we estimated its effect size (Hedges' $g$ ) for each articulator-discriminative site at each time point $(n=51, \Delta t=40$ $\mathrm{ms}$ ) within the $2 \mathrm{~s}$ interval centered at vowel onset. Effect sizes indicating presence of articulatory discrimination at a given time point are plotted in Figure $5 D$. In contrast to the timing of the overall high-gamma activity in sensorimotor cortex, which peaked near vowel onset, the greatest articulatory discrimination was observed near consonant onset (mean time $=-0.12 \mathrm{~s}, \mathrm{SD}=$ 0.09 ). Maximum discrimination was observed even earlier in the $\mathrm{STN}, \sim 120 \mathrm{~ms}$ before consonant onset (mean time $=-0.24 \mathrm{~s}$, $\mathrm{SD}=0.14): t_{(25.1)}=3.19, p=0.004$ (Fig. $\left.5 D\right)$, where the mean magnitude of the effect also was significantly greater (mean = $1.94, \mathrm{SD}=1.01)$ than in sensorimotor sites $($ mean $=1.06, \mathrm{SD}=$ $\left.0.84): t_{(29.02)}=-3.2, p=0.003\right)$.

\section{Discussion}

We analyzed LFPs obtained from the simultaneous recording of the cortical and STN activity in 11 human subjects with Parkinson's disease while they participated in a speech task during subcortical mapping for the implantation of DBS electrodes. We selected the speech stimuli such that articulation of the initial consonant engaged either tongue or lip musculature to determine whether encoding of speech articulators, similar to that previously reported for the sensorimotor cortex, is represented in subthalamic high-gamma activity. We found that STN highgamma activity tracks speech production at the level of vocal tract 
articulators, which occurs before the onset of vocalization and often before related cortical encoding.

\section{Speech-related activation}

We found that speech production was accompanied by significant time-frequency modulations in both the STN and the sensorimotor cortex, namely, suppression of alpha and beta activity and increase in high-gamma activity $(>50 \mathrm{~Hz})$. In both cases, significant time-frequency modulations emerged $\sim 400 \mathrm{~ms}$ before spoken response onset and persisted throughout the execution of speech. Decrease of activity in the alpha and beta bands and increase of activity in high-frequency bands have been previously reported as markers of ongoing movement and movement-related patterns in the STN (Androulidakis et al., 2007; Kempf et al., 2007; Lipski et al., 2017; Geng et al., 2018; Lofredi et al., 2018). However, only modulation of beta activity during speech production has been reported (Hebb et al., 2012). Therefore, our results provide the first demonstration of evoked increases in STN high-gamma activity before and during speech production. Importantly, we show that the power of high-gamma response changes significantly along the dorsal-ventral plane of the MNI-defined locations of the STN electrodes, with greater high-gamma power observed dorsally. This finding agrees with recent demonstration that subthalamic gamma power is greatest in the sensorimotor part of the STN (Lofredi et al., 2018). Therefore, in light of the existing conception of the parcellated organization of the STN into sensorimotor, associative, and limbic areas (Hamani et al., 2004; Temel et al., 2005; Haynes and Haber, 2013), our results show that articulatory aspects of speech recruit the sensorimotor region of the STN and are consistent with our previous findings showing speech-related increases in the firing rate of human STN neurons (Lipski et al., 2018). In contrast to the STN, the magnitude of cortical high-gamma activity was not significantly different across recording locations. Given that the cortical recordings were confined to the orofacial segment of the sensorimotor cortex and the evidence of overlapping speechrelated activation in the precentral and postcentral gyri (Penfield and Boldrey, 1937; Bouchard et al., 2013; Breshears et al., 2015), this lack of spatial differentiation in the cortical high-gamma activity is not unexpected.

\section{Encoding of speech articulators}

To further quantify the observed speech-related high-gamma modulation in the STN and the sensorimotor cortex, we investigated whether the two structures showed encoding specific to speech articulators. For the sensorimotor cortex, we found that $30 \%$ of recording sites revealed either lip-preferred or tonguepreferred activity, which had a topographic distribution: the electrodes located more dorsally on the sensorimotor cortex produced a greater high-gamma power during the articulation of lip consonants, whereas the electrodes that were located more ventrally yielded a greater high-gamma power for tongue consonants. Therefore, our results appear to recapitulate the dorsalventral layout for lips and tongue representations within the sensorimotor cortex (Penfield and Boldrey, 1937; Bouchard et al., 2013; Breshears et al., 2015; Chartier et al., 2018; Conant et al., 2018). We found that articulatory encoding is closely aligned with the consonant onset in acoustic speech production. This discriminative activity began to emerge $\sim 500 \mathrm{~ms}$ before articulation, suggesting the potential encoding of pre-articulatory preparatory processes such as planning a motor command and retrieving the sensory representation of the intended articulatory target (Guenther et al., 2006). For the STN, we found that $23 \%$ of recording locations showed articulator-discriminative activity, but without articulatory somatotopy. Previous studies demonstrating functional organization in the STN of human and nonhuman primates have used single-unit recordings to demonstrate a crude somatotopy for arm-related and leg-related movements (Monakow et al., 1978; DeLong et al., 1985; Wichmann et al., 1994; Nambu et al., 1996; Rodriguez-Oroz et al., 2001; Starr et al., 2003; Theodosopoulos et al., 2003), although representations for face, eyes, and finer-grained movements with shoulders, elbows, knees, wrists, etc. have been less somatotopically consistent (DeLong et al., 1985; Wichmann et al., 1994). It should be noted that LFP recordings might not be expected to delineate a functional somatotopy due to their representation of group-level neuronal activity recorded from a much larger volume of tissue than the signal obtained from microelectrode recordings. In this respect, it is remarkable that we found evidence for articulator-level encoding in the LFP signal, which may indicate the encoding of aspects of speech production that are specific to these articulatory maneuvers but separate from their anatomical representation at the cortical level.

The time course of the articulatory encoding in the STN further supports a differentiation from sensorimotor cortex. We found that high-gamma activity at articulator-discriminative STN recording sites had two peaks $\sim 320 \mathrm{~ms}$ apart: an early one $(\sim 80 \mathrm{~ms})$ before acoustically defined speech onset and a later one $(\sim 240 \mathrm{~ms})$ after speech onset. Because all stimulus words were of the CVC type, such pattern of activity may reflect a transient rather than a sustained type of activation at consonant onsets (Salari et al., 2018). Alternatively, the second peak of activity could be vowel related because some of the stimulus vowels included articulation with lips in addition to tongue movements (e.g., lip rounding in $/ u / /$ ). It is also possible that the observed pattern of activity in the STN reflects activity from multiple populations of neurons with different speech-related functions that manifests itself with different peak latencies. However, because the stimuli were not designed to tease apart these influences, a definitive conclusion cannot be drawn from the data. We also found that articulatory discrimination reflected in STN highgamma activity was not maximal near consonant onset, as occurred in the sensorimotor cortex, but rather peaked $\sim 120 \mathrm{~ms}$ before its acoustic production, suggesting the possible involvement of the STN in articulator-specific planning (Fig. 5D). Although the finding of the relative temporal differences in the articulatory encoding between the sensorimotor cortex and the STN is important, it is worth noting that we relied upon the phonetic coding of the produced acoustics to infer which articulators were involved in consonant productions as in Bouchard et al. (2013). For a more precise characterization of the temporal aspects of the articulatory encoding, direct measurements of articulatory kinematics would be necessary, which were beyond the scope of the present study and are difficult to implement during DBS surgery. Therefore, it remains to be established whether the observed articulator-related STN activity is indicative of the activation of musculature engaged in articulation and of a more mechanistic involvement of STN in speech articulation or of its role in higher-order articulation-related processes such as speech planning, control of kinematic trajectories, and switching between motor commands.

\section{Limitations}

We acknowledge that the disease state is a potential confound to our results. We do not report control data collected from a nonParkinson's population. Given that basal ganglia activity in Par- 
kinson's disease patients is characterized by reorganization of receptive fields and loss of specificity (Abosch et al., 2002; Hamani et al., 2004), we may be assessing an unknown amount of cross-talk or "motor overflow" of the signal related to different body parts (Bergman et al., 1998; Nambu, 2011). Additionally, we searched for articulator-specific somatotopy on the basis of 79 available STN recording locations with nonsystematic spatial separation, which may represent inadequate sampling. Note that fine-wire EMG is not an option in awake neurosurgical patients, so our experimental design did not allow us to measure articulatory muscle movement for correlation with intracranial signals. The potential encoding of other linguistic features, such as manner of articulation, also is an interesting area for future study, but our stimulus set does not systematically sample them to adequately address it. In ongoing work, we have developed new materials that more systematically engage consonant feature space, including manner, as well as vowel features, in the context of two behaviors: listening to speech and articulation of speech.

\section{Summary}

These data are the first to demonstrate time-frequency modulations in STN activity that track articulatory aspects of speech, complementing recent evidence for speech-related changes in the timing and the firing rate of the STN neurons (Lipski et al., 2018). A major strength of this study is the application of a single analytic approach to simultaneous LFP recordings from the sensorimotor cortex and the STN, which allowed us to compare the neural activity in these brain regions during speech. After demonstrating the expected somatotopic differentiation of vocal tract articulators in the sensorimotor cortex, we showed that the STN also differentially encodes speech articulators with more detailed temporal patterning that does not mirror cortical activity. Further elucidation of the role of cortico-basal ganglia interactions in the speech production network will be critical for improving our understanding of the neurobiology of speech dysfunction in basal ganglia disorders and related future treatments.

\section{References}

Abosch A, Hutchison WD, Saint-Cyr JA, Dostrovsky JO, Lozano AM (2002) Movement-related neurons of the subthalamic nucleus in patients with parkinson disease. J Neurosurg 97:1167-1172.

Akaike H (1974) A new look at the statistical model identification. IEEE Transactions on Automatic Control 19:716-723.

Aldridge D, Theodoros D, Angwin A, Vogel AP (2016) Speech outcomes in Parkinson's disease after subthalamic nucleus deep brain stimulation: a systematic review. Parkinsonism Relat Disord 33:3-11.

Alexander GE, DeLong MR, Strick PL (1986) Parallel organization of functionally segregated circuits linking basal ganglia and cortex. Annu Rev Neurosci 9:357-381.

Androulidakis AG, Kühn AA, Chen CC, Blomstedt P, Kempf F, Kupsch A, Schneider GH, Doyle L, Dowsey-Limousin P, Hariz MI, Brown P (2007) Dopaminergic therapy promotes lateralized motor activity in the subthalamic area in Parkinson's disease. Brain 130:457-468.

Bates D, Maechler M, Bolker B, Walker S (2015) Fitting linear mixed-effects models using lme4. Journal of Statistical Software 67:1-48.

Benjamini Y, Hochberg Y (1995) Controlling the false discovery rate: a practical and powerful approach to multiple testing. Journal of the Royal Statistical Society 57:289-300.

Bergman H, Feingold A, Nini A, Raz A, Slovin H, Abeles M, Vaadia E (1998) Physiological aspects of information processing in the basal ganglia of normal and parkinsonian primates. Trends Neurosci 21:32-38.

Bouchard KE, Chang EF (2014) Control of spoken vowel acoustics and the influence of phonetic context in human speech sensorimotor cortex. J Neurosci 34:12662-12677.

Bouchard KE, Mesgarani N, Johnson K, Chang EF (2013) Functional organization of human sensorimotor cortex for speech articulation. Nature 495:327-332.
Bouchard KE, Conant DF, Anumanchipalli GK, Dichter B, Chaisanguanthum KS, Johnson K, Chang EF (2016) High-resolution, non-invasive imaging of upper vocal tract articulators compatible with human brain recordings. PLoS One 11:e0151327.

Brainard DH (1997) The psychophysics toolbox. Spat Vis 10:433-436.

Breshears JD, Molinaro AM, Chang EF (2015) A probabilistic map of the human ventral sensorimotor cortex using electrical stimulation. J Neurosurg 123:340-349.

Brown S, Ngan E, Liotti M (2008) A larynx area in the human motor cortex. Cereb Cortex 18:837-845.

Brunner RJ, Kornhuber HH, Seemüller E, Suger G, Wallesch CW (1982) Basal ganglia participation in language pathology. Brain Lang 16:281-299.

Carey D, Krishnan S, Callaghan MF, Sereno MI, Dick F (2017) Functional and quantitative MRI mapping of somatomotor representations of human supralaryngeal vocal tract. Cereb Cortex 27:265-278.

Chartier J, Anumanchipalli GK, Johnson K, Chang EF (2018) Encoding of articulatory kinematic trajectories in human speech sensorimotor cortex. Neuron 98:1042-1054.e4.

Cheung C, Hamiton LS, Johnson K, Chang EF (2016) The auditory representation of speech sounds in human motor cortex. Elife 5:e12577.

Conant DF, Bouchard KE, Leonard MK, Chang EF (2018) Human sensorimotor cortex control of directly measured vocal tract movements during vowel production. J Neurosci 38:2955-2966.

Crone NE, Miglioretti DL, Gordon B, Lesser RP (1998) Functional mapping of human sensorimotor cortex with electrocorticographic spectral analysis: II. event-related synchronization in the gamma band. Brain 121:23012315 .

Damasio AR, Damasio H, Rizzo M, Varney N, Gersh F (1982) Aphasia with nonhemorrhagic lesions in the basal ganglia and internal capsule. Arch Neurol 39:15-24.

DeLong MR, Crutcher MD, Georgopoulos AP (1985) Primate globus pallidus and subthalamic nucleus: functional organization. J Neurophysiol 53:530-543.

Edwards E, Soltani M, Deouell LY, Berger MS, Knight RT (2005) Highgamma activity in response to deviant auditory stimuli recorded directly from human cortex. J Neurophysiol 94:4269-4280.

Ewert S, Plettig P, Li N, Chakravarty MM, Collins DL, Herrington TM, Kühn AA, Horn A (2018) Toward defining deep brain stimulation targets in MNI space: A subcortical atlas based on multimodal MRI, histology and structural connectivity. Neuroimage 170:271-282.

Geng X, Xu X, Horn A, Li N, Ling Z, Brown P, Wang S (2018) Intraoperative characterisation of subthalamic oscillations in Parkinson's disease. Clin Neurophysiol 129:1001-1010.

Guenther FH, Ghosh SS, Tourville JA (2006) Neural modeling and imaging of the cortical interactions underlying syllable production. Brain Lang 96:280-301.

Hamani C, Saint-Cyr JA, Fraser J, Kaplitt M, Lozano AM (2004) The subthalamic nucleus in the context of movement disorders. Brain 127:4-20.

Haynes WI, Haber SN (2013) The organization of prefrontal-subthalamic inputs in primates provides an anatomical substrate for both functional specificity and integration: implications for basal ganglia models and deep brain stimulation. J Neurosci 33:4804-4814.

Hebb AO, Darvas F, Miller KJ (2012) Transient and state modulation of beta power in human subthalamic nucleus during speech production and finger movement. Neuroscience 202:218-233.

Hedges LV (1981) Distribution theory for Glass' estimator of effect size and related estimators. Journal of Educational Statistics 6:107-128.

Hesselmann V, Sorger B, Lasek K, Guntinas-Lichius O, Krug B, Sturm V, Goebel R, Lackner K (2004) Discriminating the cortical representation sites of tongue and lip movement by functional MRI. Brain Topography 16:159-167.

Ho AK, Iansek R, Marigliani C, Bradshaw JL, Gates S (1998) Speech impairment in a large sample of patients with Parkinson's disease. Behav Neurol 11:131-137.

Horn A, Kühn AA (2015) Lead-DBS: a toolbox for deep brain stimulation electrode localizations and visualizations. Neuroimage 107:127-135.

Horn A, Li N, Dembek TA, Kappel A, Boulay C, Ewert S, Tietze A, Husch A, Perera T, Neumann WJ, Reisert M, Si H, Oostenveld R, Rorden C, Yeh FC, Fang Q, Herrington TM, Vorwerk J, Kühn AA (2019) Lead-DBS v2: Toward a comprehensive pipeline for deep brain stimulation imaging. Neuroimage 184:293-316. 
Kempf F, Kühn AA, Kupsch A, Brücke C, Weise L, Schneider GH, Brown P (2007) Premovement activities in the subthalamic area of patients with Parkinson's disease and their dependence on task. Eur J Neurosci 25:3137-3145.

Knowles T, Adams S, Abeyesekera A, Mancinelli C, Gilmore G, Jog M (2018) Deep brain stimulation of the subthalamic nucleus parameter optimization for vowel acoustics and speech intelligibility in Parkinson's disease. J Speech Lang Hear Res 61:510-524.

Kuznetsova A, Brockhoff PB, Christensen RHB (2017) lmerTest package: tests in linear mixed effects models. Journal of Statistical Software 82:1-26.

Lee PS, Weiner GM, Corson D, Kappel J, Chang YF, Suski VR, Berman SB, Homayoun H, Van Laar AD, Crammond DJ, Richardson RM (2018) Outcomes of interventional-MRI versus microelectrode recordingguided subthalamic deep brain stimulation. Front Neurol 9:241.

Lipski WJ, Wozny TA, Alhourani A, Kondylis ED, Turner RS, Crammond DJ, Richardson RM (2017) Dynamics of human subthalamic neuron phaselocking to motor and sensory cortical oscillations during movement. J Neurophysiol 118:1472-1487.

Lipski WJ, Alhourani A, Pirnia T, Jones PW, Dastolfo-Hromack C, Helou LB, Crammond DJ, Shaiman S, Dickey MW, Holt LL, Turner RS, Fiez JA, Richardson RM (2018) Subthalamic nucleus neurons differentially encode early and late aspects of speech production. J Neurosci 38:5620-5631.

Lofredi R, Neumann WJ, Bock A, Horn A, Huebl J, Siegert S, Schneider GH, Krauss JK, Kühn AA (2018) Dopamine-dependent scaling of subthalamic gamma bursts with movement velocity in patients with Parkinson's disease. Elife 7:e31895.

Logemann JA, Fisher HB, Boshes B, Blonsky ER (1978) Frequency and cooccurrence of vocal tract dysfunctions in the speech of a large sample of Parkinson patients. J Speech Hear Disord 43:47-57.

Lotte F, Brumberg JS, Brunner P, Gunduz A, Ritaccio AL, Guan C, Schalk G (2015) Electrocorticographic representations of segmental features in continuous speech. Front Hum Neurosci 9:97.

Lotze M, Seggewies G, Erb M, Grodd W, Birbaumer N (2000) The representation of articulation in the primary sensorimotor cortex. Neuroreport 11:2985-2989.

Meier JD, Aflalo TN, Kastner S, Graziano MS (2008) Complex organization of human primary motor cortex: a high-resolution fMRI study. J Neurophysiol 100:1800-1812.

Monakow KH, Akert K, Künzle H (1978) Projections of the precentral motor cortex and other cortical areas of the frontal lobe to the subthalamic nucleus in the monkey. Exp Brain Res 33:395-403.

Moore MW, Fiez JA, Tompkins CA (2017) Consonant age-of-acquisition effects in nonword repetition are not articulatory in nature. J Speech Lang Hear Res 60:3198-3212.

Morrison CE, Borod JC, Perrine K, Beric A, Brin MF, Rezai A, Kelly P, Sterio D, Germano I, Weisz D, Olanow CW (2004) Neuropsychological functioning following bilateral subthalamic nucleus stimulation in Parkinson's disease. Arch Clin Neuropsychol 19:165-181.

Mugler EM, Patton JL, Flint RD, Wright ZA, Schuele SU, Rosenow J, Shih JJ, Krusienski DJ, Slutzky MW (2014) Direct classification of all American English phonemes using signals from functional speech motor cortex. Journal of Neural Engineering 11:035015.

Nadeau SE, Crosson B (1997) Subcortical aphasia. Brain Lang 58:355-402; discussion 418-423.

Nambu A (2011) Somatotopic organization of the primate basal ganglia. Front Neuroanat 5:26.

Nambu A, Takada M, Inase M, Tokuno H (1996) Dual somatotopical representations in the primate subthalamic nucleus: evidence for ordered but reversed body-map transformations from the primary motor cortex and the supplementary motor area. J Neurosci 16:2671-2683.

Oostenveld R, Fries P, Maris E, Schoffelen JM (2011) FieldTrip: open source software for advanced analysis of MEG, EEG, and invasive electrophysiological data. Comput Intell Neurosci 2011:156869.

Penfield W (1954) Mechanisms of voluntary movement. Brain 77:1-17.

Penfield W, Boldrey E (1937) Somatic motor and sensory representation in the cerebral cortex of man as studied by electrical stimulation. Brain 60:389-443.

Pulvermüller F, Huss M, Kherif F, Moscoso del Prado Martin F, Hauk O, Shtyrov Y (2006) Motor cortex maps articulatory features of speech sounds. Proc Natl Acad Sci U S A 103:7865-7870.

R Core Team (2018) R: A language and environment for statistical computing. Vienna: R Foundation for Statistical Computing. Available at: https://www.R-project.org/.

Ramsey NF, Salari E, Aarnoutse EJ, Vansteensel MJ, Bleichner MG, Freudenburg ZV (2018) Decoding spoken phonemes from sensorimotor cortex with high-density ECoG grids. Neuroimage 180:301-311.

Randazzo MJ, Kondylis ED, Alhourani A, Wozny TA, Lipski WJ, Crammond DJ, Richardson RM (2016) Three-dimensional localization of cortical electrodes in deep brain stimulation surgery from intraoperative fluoroscopy. Neuroimage 125:515-521.

Rodriguez-Oroz MC, Rodriguez M, Guridi J, Mewes K, Chockkman V, Vitek J, DeLong MR, Obeso JA (2001) The subthalamic nucleus in Parkinson's disease: somatotopic organization and physiological characteristics. Brain 124:1777-1790

Salari E, Freudenburg ZV, Vansteensel MJ, Ramsey NF (2018) Spatialtemporal dynamics of the sensorimotor cortex: sustained and transient activity. IEEE Transactions on Neural Systems and Rehabilitation Engineering 26:1084-1092.

Sawilowsky S (2009) New effect size rules of thumb. Journal of Modern Applied Statistical Methods 8:467-474.

Starr PA, Theodosopoulos PV, Turner R (2003) Surgery of the subthalamic nucleus: use of movement-related neuronal activity for surgical navigation. Neurosurgery 53:1146-1149.

Tadel F, Baillet S, Mosher JC, Pantazis D, Leahy RM (2011) Brainstorm: a user-friendly application for MEG/EEG analysis. Comput Intell Neurosci 2011:879716.

Takai O, Brown S, Liotti M (2010) Representation of the speech effectors in the human motor cortex: somatotopy or overlap? Brain Lang 113:39-44.

Temel Y, Blokland A, Steinbusch HW, Visser-Vandewalle V (2005) The functional role of the subthalamic nucleus in cognitive and limbic circuits. Prog Neurobiol 76:393-413.

Theodosopoulos PV, Marks WJ Jr, Christine C, Starr PA (2003) The locations of movement-related cells in the human subthalamic nucleus in Parkinson's disease. Mov Disord 18:791-798.

Wallesch CW, Kornhuber HH, Brunner RJ, Kunz T, Hollerbach B, Suger G (1983) Lesions of the basal ganglia, thalamus, and deep white matter: differential effects on language functions. Brain Lang 20:286-304.

Walsh B, Smith A (2012) Basic parameters of articulatory movements and acoustics in individuals with Parkinson's disease. Mov Disord 27:843-850.

Watson P, Montgomery EB Jr (2006) The relationship of neuronal activity within the sensori-motor region of the subthalamic nucleus to speech. Brain Lang 97:233-240.

Wichmann T, Bergman H, DeLong MR (1994) The primate subthalamic nucleus. I. Functional properties in intact animals. J Neurophysiol 72:494-506.

Witt K, Daniels C, Reiff J, Krack P, Volkmann J, Pinsker MO, Krause M, Tronnier V, Kloss M, Schnitzler A, Wojtecki L, Bötzel K, Danek A, Hilker R, Sturm V, Kupsch A, Karner E, Deuschl G (2008) Neuropsychological and psychiatric changes after deep brain stimulation for Parkinson's disease: a randomised, multicentre study. Lancet Neurol 7:605-614.

Woolsey CN, Erickson TC, Gilson WE (1979) Localization in somatic sensory and motor areas of human cerebral cortex as determined by direct recording of evoked potentials and electrical stimulation. J Neurosurg $51: 476-506$. 